\title{
CARACTERIZAÇÃO MORFOLÓGICA DA PLATAFORMA CONTINENTAL DE ICAPUÍ UTILIZANDO DADOS BATIMÉTRICOS
}

\author{
João Capistrano de Abreu Neto ${ }^{1}$, \\ George Satander Sá Freire ${ }^{2}$, \\ Daniel de Ponti Souza ${ }^{2}$ \\ Guilherme Augusto Mendonça Maia²
}

\subsection{0/1980-8208/estudosgeologicos.v29n2p3-16}

1 Programa de Pós-graduação em Geologia, Centro de Ciências, UFC (joaoabreuneto@gmail.com)

2 Departamento de Geologia, Centro de Ciências, UFC (freire@ufc.br, danieldeponti@hotmail.com, guilherme.maiageo@gmail.com)

\section{RESUMO}

Os levantamentos batimétricos se apresentam como uma ferramenta através da qual podemos obter informações morfológicas, como perfis batimétricos, modelos digitais de terreno, declividade e orientação do relevo, possuindo aplicações como a identificação de bancos de areia, obras de engenharia, cartas de navegação e estudos ambientais. Trabalhos anteriores acerca da morfologia da plataforma continental de Icapuí, onde foram realizados levantamentos batimétricos no setor oeste da plataforma interna, identificaram afloramentos rochosos, resultados de variações da linha de costa, testemunhos das falésias que resistiram aos processos costeiros atuantes na região e um campo de dunas submersas. Devido à falta de uma caracterização da plataforma como um todo, este trabalho tem como objetivo a caracterização morfológica da plataforma continental do município de Icapuí com o uso de dados batimétricos para assim, identificar as formas de fundo mais expressivas da área. Assim, foi possível caracterizar a morfologia da área, que se apresenta predominantemente plana com baixa declividade, sendo mais estreita e menos profunda do que média do resto do estado do Ceará, com aproximadamente $45 \mathrm{~km}$ de extensão e com a zona de quebra da plataforma com profundidade média de $45 \mathrm{~m}$. Ainda foram identificados na plataforma interna cristas de praia submersas e uma quebra na continuidade do relevo, que possibilita dividir a área em setores leste e oeste. Foram obtidos resultados satisfatórios, tornando possível identificar as estruturas mais expressivas da área, sendo possível relacioná-las com as flutuações do nível mar, tornando a região de interesse para a compreensão de tais eventos.

Palavras Chave: Batimetria. Morfologia. Plataforma continental. Flutuações do nível do mar. Icapuí.

\section{ABSTRACT}

The bathymetric surveys are presented as a tool through which we can obtain morphological information, such as bathymetric profiles, digital terrain models, slope and relief orientation, having applications such as identification of sandbanks, engineering works, navigation charts and environmental studies. Previous works on the morphology of the continental shelf of Icapuí, where bathymetric surveys were carried out in the western sector of the inner platform, identified rocky outcrops, results of coastline variations, cliff testimonies that resisted coastal processes in the region and a field of submerged dunes. Due to a lack of a characterization of the platform as a whole, this work 


\section{João Capistrano de Abreu Neto et al.}

aims at the morphological characterization of the continental shelf of the city of Icapuí using bathymetric data to identify the most expressive bottom forms of the area. This way, it was possible to characterize the morphology of the area, which is predominantly flat with low slope, being narrower and shallower than the average of the rest of the state of Ceará, with approximately $45 \mathrm{~km}$ long and with the shelf breaking zone with average depth of $45 \mathrm{~m}$. There were still identified in the inner platform submerged beach ridges and a break in the continuity of the relief, that makes it possible to divide the area in east and west sectors. Satisfactory results were obtained, making it possible to identify the most expressive structures in the area, being possible to relate them to the sea level fluctuations, making the region of interest for the understanding of such events.

Keywords: Bathymetry. Morphology. Continental shelf. Sea level fluctuations. Icapuí.

\section{INTRODUÇÃO}

As margens continentais constituem-se em unidades de transição entre os continentes e as bacias oceânicas e são consideradas, do ponto de vista geológico, prolongamentos das plataformas continentais que se localizam abaixo do nível dos oceanos (Tessler \& Mahiques, 2003; Batista Neto \& Silva, 2004).

As margens continentais representam $20 \%$ do total da área ocupada pelos oceanos (Kennett, 1982) e podem ser agrupadas em dois tipos principais, de acordo com sua morfologia e evolução tectônica: as margens do "tipo Atlântico" (Passivas ou divergentes - são mais extensas e estáveis, caracterizando-se pelo considerável acúmulo de sedimentos) e do "tipo Pacífico" (Ativas ou convergentes - são mais estreitas e com intensa atividade tectônica de vulcanismo e terremotos, dobramentos, falhamentos e outros processos geomorfológicos).

Para Coutinho (1996), a plataforma continental constitui a faixa mais rasa que circunda a maioria dos continentes, tendo a configuração de tabuleiro ou terraço, e termina em direção ao mar com um aumento acentuado da inclinação denominado "quebra da plataforma", que marca o limite externo da plataforma continental. Possui a superfície plana, quase horizontal, suavemente inclinada mar adentro, estando a uma profundidade média de quebra em tomo de $130 \mathrm{~m}$. A plataforma continental representa o prolongamento do próprio continente e devido à sua importância econômica e estratégica é a província oceânica mais estudada.

Freire (1985) afirma que a representação da morfologia de fundo da margem continental é feita através de representação gráfica plana das unidades topográficas, que assim nos fornece a atual morfologia do fundo do mar, podendo incluir outras características superficiais, indicativas de forma $\mathrm{e}$ tendências batimétricas do relevo.

Dessa maneira, os levantamentos batimétricos e o estudo da morfologia de fundo se apresentam como uma ferramenta importante, tendo em vista que, através dela, podemos obter informações morfológicas, como perfis batimétricos, modelos digitais de terreno, declividade e orientação do relevo, que possuem diversas aplicações como a identificação de bancos de areia, obras de engenharia, cartas de navegação, estudos ambientais, entre outros.

\section{ÁREA， MATERIAL E MÉTODOS}

\section{Área de estudo}


A área de estudo (Fig. 1) se localiza no extremo leste do estado do Ceará, na fronteira com o estado do Rio Grande do Norte e está inserida no contexto geológico da Bacia Potiguar. Esta compreende uma parte emersa e outra submersa, ocupando grande parte do Estado do Rio Grande do Norte e uma pequena porção do Estado do
Ceará. Geologicamente, limita-se a sul, leste e oeste pelo embasamento cristalino, sendo que o Alto de Fortaleza, a oeste, define seu limite com a Bacia do Ceará. Sua área, até a isóbata de $3.000 \mathrm{~m}$, alcança 119.295 $\mathrm{km}^{2}$, sendo $33.200 \mathrm{~km}^{2} \quad(27,8 \%)$ emersos e $86.095 \mathrm{~km}^{2} \quad(72,2 \%)$ submersos. (ANP, 2016).

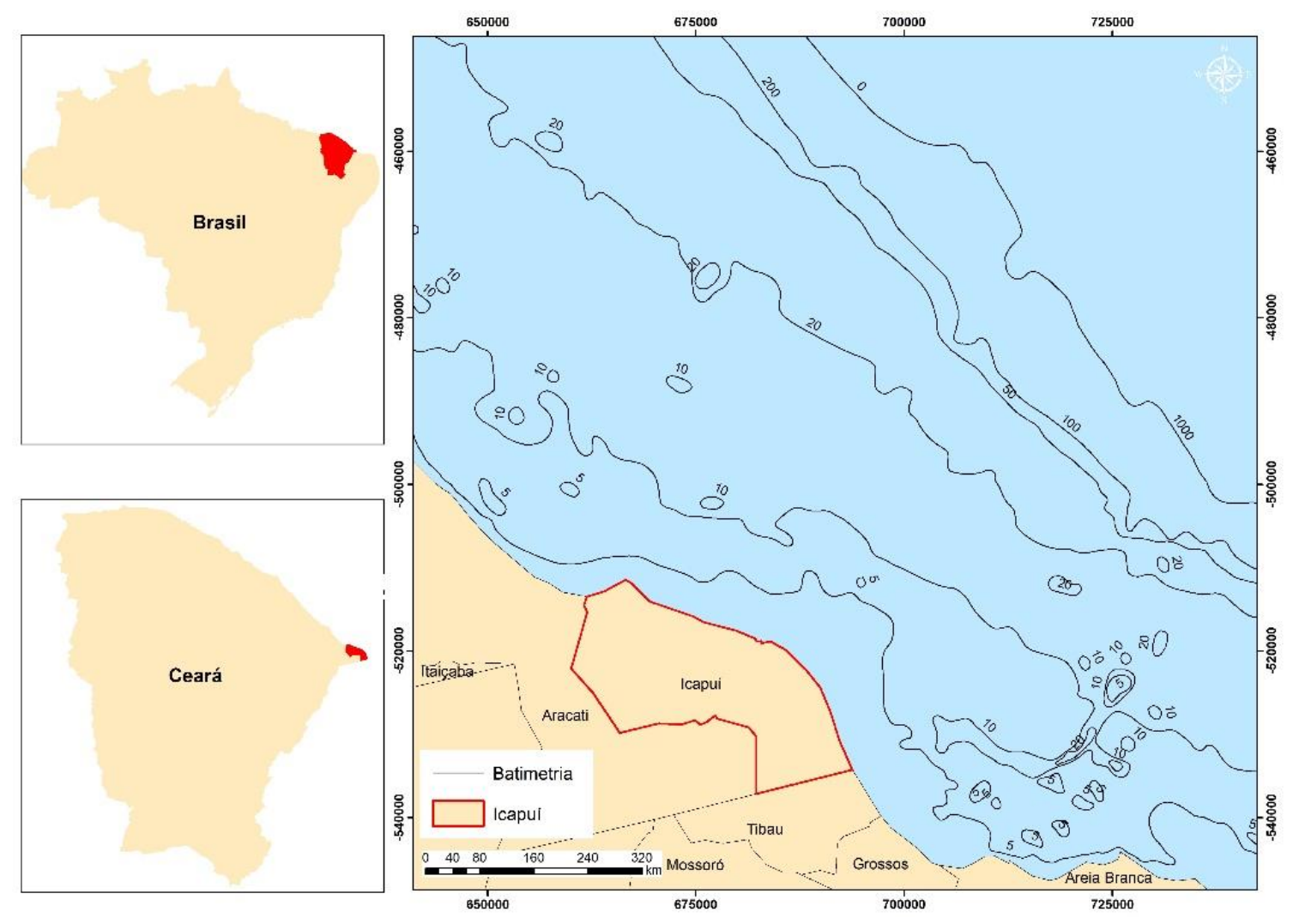

Figura 1 - Localização da área de estudo. Fonte: Autor.

Já foram realizados alguns trabalhos acerca da morfologia da plataforma continental de Icapuí, a exemplo dos trabalhos de Oliveira (2009), que identificou alguns afloramentos na plataforma interna $\mathrm{e}$ dois mais extensos, correlacionados com variações do nível do mar na plataforma externa no setor oeste da plataforma e Monteiro (2011), que realizou um levantamento de detalhe do campo de dunas submersas. Ainda vale destacar os trabalhos de Oliveira (2012) e Barros (2014), que realizaram levantamentos batimétricos no setor oeste da plataforma continental interna, identificando a presença de inúmeros afloramentos rochosos de menor expressão, resultados de variações da linha de costa e testemunhos das falésias que resistiram aos processos costeiros atuantes na região.

Meireles (2012), afirma que ao serem analisadas as cotas batimétricas diante do banco de algas dos Cajuais e ao longo da plataforma continental de parte do litoral leste do Ceará foram verificadas fisionomias associadas a 
antigos níveis de base, atualmente submersos e relacionados a linhas de costa durante as fases transgressivas e regressivas no nível do mar.

Assim, tendo em vista que os trabalhos anteriormente realizados se dedicaram a recortes menores dentro da área de estudo, este trabalho tem como objetivo o uso de dados batimétricos para realizar uma caracterização morfológica da plataforma continental do município de Icapuí, identificando as formas de fundo mais expressivas da área.

\section{Métodos}

A pesquisa foi realizada em três fases: referencial bibliográfico, aquisição e processamento de dados batimétricos e integração e análise dos resultados obtidos. E objetivou uma análise da morfologia da plataforma continental, através da geração de perfis batimétricos, geração de curvas de nível e modelagem digital do terreno.

Os dados (Fig. 2) foram adquiridos através do acervo do Laboratório de Geologia Marinha e Aplicada - LGMA e validados através das cartas náuticas da Diretoria de Hidrografia e Navegação DHN, que foram integrados e utilizados para a geração da batimetria da área, representadas através de isolinhas, modelos digitais de terreno (MDT) e mapas de declividade, sendo utilizados para a caracterização morfológica da área e delimitação da plataforma continental, através da identificação das principais feições submersas e da zona de que quebra, que representa o limite entre a plataforma continental e o talude continental.

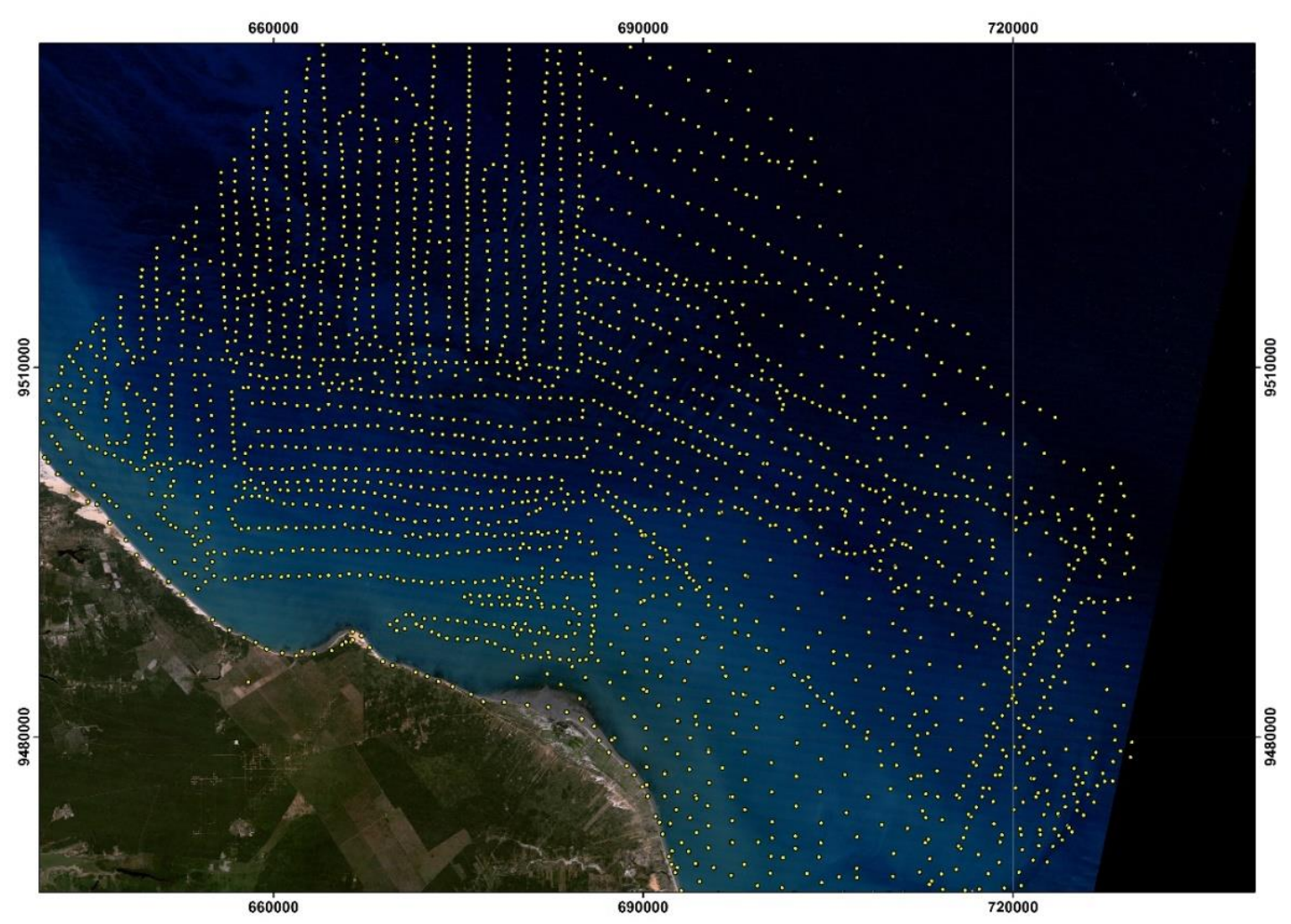

Figura 2 - Mapa de pontos batimétricos utilizados da área de estudo.

Para tal, utilizou-se o método geoestatístico da Krigagem universal para criar uma superfície de interpolação, a partir dos dados batimétricos filtrados até a profundidade de 300 metros, englobando dessa maneira, toda a área da plataforma continental e a zona de quebra. 
O método da Krigagem Universal utiliza modelos estatísticos que permitem uma variedade de resultados, neles os valores dos pontos amostrados são modelados como um polinômio de tendência, a Krigagem é realizada sobre a diferença desta e os valores dos pontos. Ainda geraram-se os contornos (isóbatas) da superfície de interpolação, a partir do Grid. As isóbatas representam uma linha de igual valor de profundidade ao longo de toda a sua extensão. Este tipo de representação foi útil para a visualização de pequenos detalhes na superfície que não são vislumbrados unicamente no tema grid. Depois que as linhas de contorno foram geradas, tevese necessidade de suavizá-las.

Para a geração do modelo digital de terreno (MDT), foi utilizado o software Surfer 11, que faz a interpolação dos dados batimétricos através de Krigagem para a geração de um grid e a partir daí são gerados mapas em perspectiva $3 \mathrm{D}$, que segundo Silveira (2014), a superfície gerada pela Krigagem permite de forma mais fidedigna, a identificação de feições geomorfológicas presentes no relevo submerso.

\section{RESULTADOS}

\section{Curvas e intervalos batimétricos}

A partir da interpolação dos dados batimétricos foi gerado um mapa de isobatimétrico com intervalo de $2 \mathrm{~m}$ até a profundidade de $100 \mathrm{~m}$ (Fig. 3).

A plataforma interna, limitada à profundidade de 18 metros, se apresenta predominantemente plana, com grau de declividade inferior a $1 \%$, possuindo uma maior inclinação na região oeste da plataforma, onde ocorre uma maior presença de afloramentos. A delimitação entre as zonas leste e oeste da plataforma fica bem evidente através de uma mudança na profundidade, possivelmente decorrente de ação estrutural, causando uma mudança abrupta não só na morfologia da plataforma como também na sedimentologia.

A plataforma externa já apresenta uma maior declividade e uma maior variedade de estruturas submersas, como os campos de dunas a oeste e um pequeno cânion a leste, que ocorre apenas próximo a zona de quebra. Logo após o campo de dunas submersas pode ser identificado um extenso afloramento que causa uma mudança abrupta por volta dos $25 \mathrm{~m}$ de profundidade, onde tal estrutura se mantém alinhada com a linha de costa atual, conforme identificado por Oliveira (2009) e Monteiro (2011). Logo após essa estrutura ainda existe uma estreita faixa de cerca de $6 \mathrm{~km}$ que define o final da plataforma continental de Icapuí, iniciando assim a zona de quebra, que se inicia na profundidade aproximada de $45 \mathrm{~m}$. 


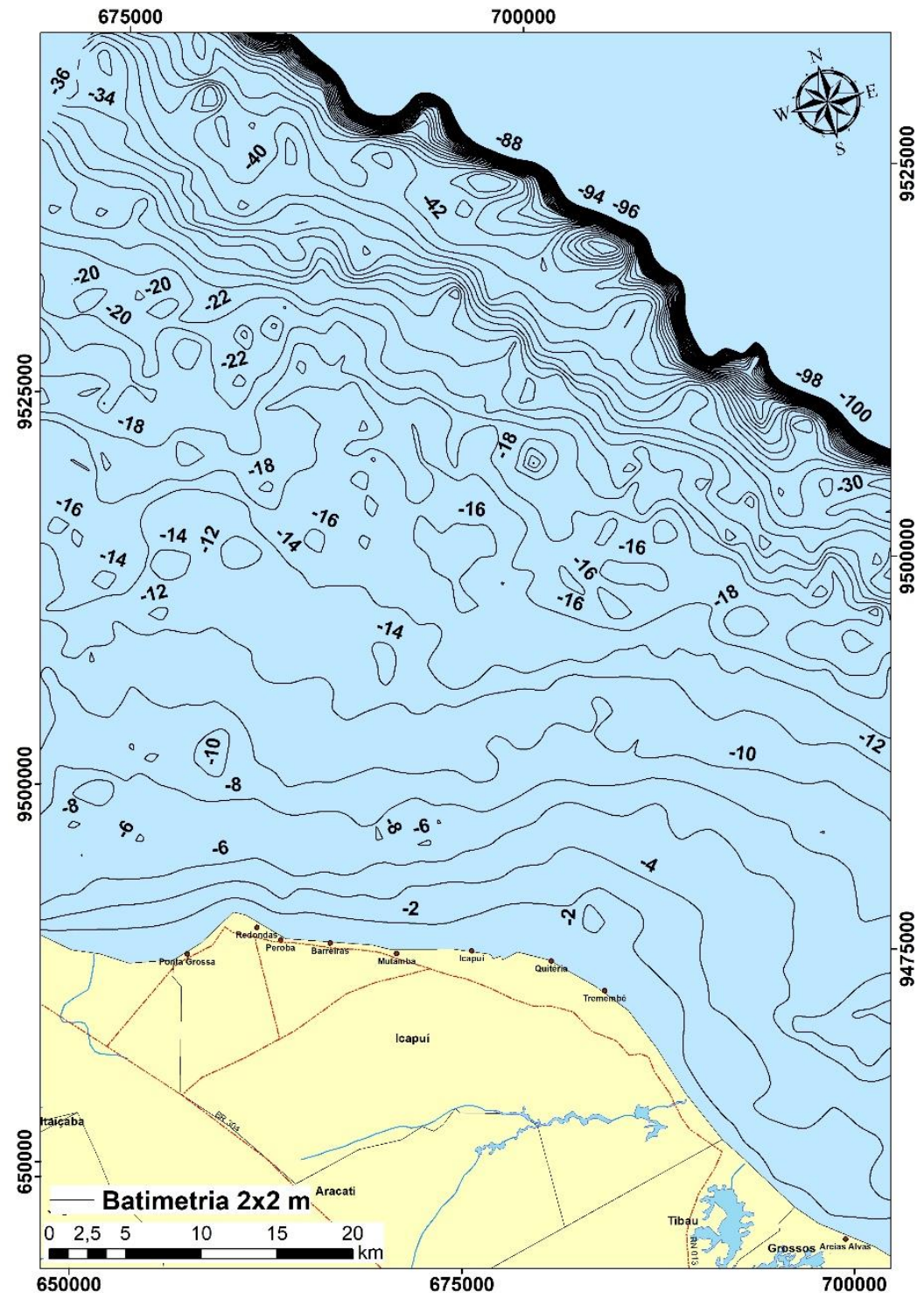

Figura 3 - Mapa isobatimétrico da plataforma continental de Icapuí. Fonte: Autor.

\section{Perfis batimétricos}

Foram traçados 6 perfis batimétricos (Fig. 4), sendo 3 perpendiculares a linha de costa e 3 paralelos, que foram de modo que fosse possível a visualização das principais características fisiográficas da plataforma continental de Icapuí e que abrangessem todas as feições identificadas nas imagens de satélite. 


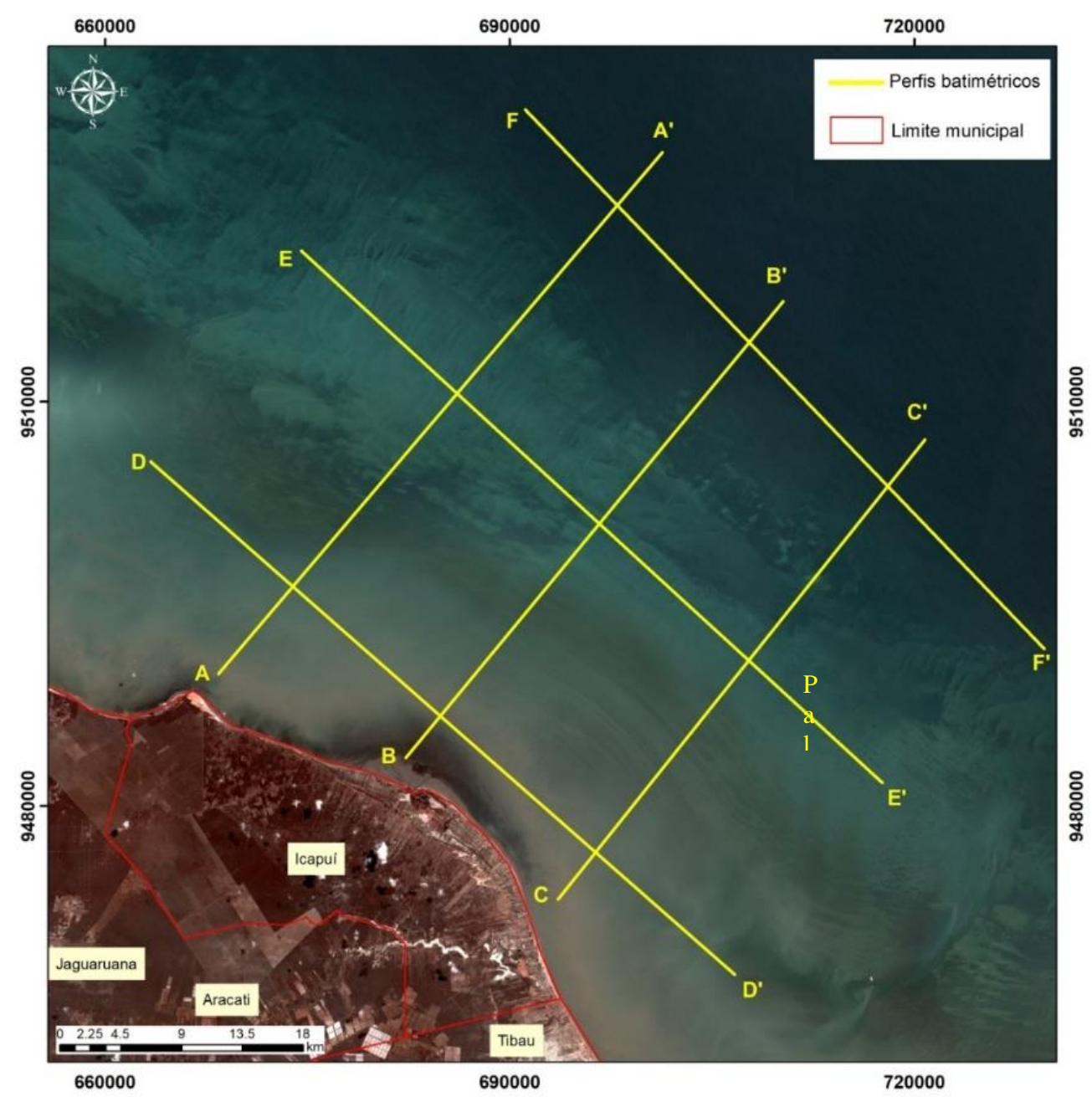

Figura 4 - Localização dos perfis batimétricos. Fonte: Autor.

Os perfis perpendiculares A-A', BB' e C-C' (Fig. 5), ressaltam o caráter plano da plataforma, apresentando sua variação morfológica mais expressiva aos $15 \mathrm{~m}$ e aos $25 \mathrm{~m}$ de profundidade devido à presença de um extenso afloramento, que segundo Monteiro (2011) apud Abreu Neto (2017), é um recife formado por rochas areníticas tabulares, com grãos de quartzo de tamanho médio, brilhosos e cimentados por carbonatos de cálcio, apresentando escarpa vertical voltada para o continente, formada pelo basculamento de blocos ocasionada pela erosão localizada no sopé, sendo ressaltado ainda que as semelhanças com as rochas de praia encontradas atualmente na linha de costa são muitas. Dessa forma é suposto que o afloramento é uma forma residual de uma antiga linha de costa em função das flutuações do nível mar.

Observando os perfis é possível visualizar que o afloramento ocorre na forma de "degraus", onde o primeiro se apresenta por volta dos $15 \mathrm{~m}$ de profundidade e o segundo por volta dos $25 \mathrm{~m}$. Percebe-se também, que à medida que se desloca para o setor leste da plataforma, o afloramento fica menos evidente.

Também é possível notar nos perfis A-A' e B-B', a existência de uma depressão quase na borda da plataforma com extensão de aproximadamente $2 \mathrm{~km}$ e $4 \mathrm{~km}$ respectivamente. Logo após a depressão se dá a quebra da plataforma, que ocorre a uma distância média de 45 $\mathrm{km}$ da linha de costa. 
From Pos: $685033.183,9482125.429$

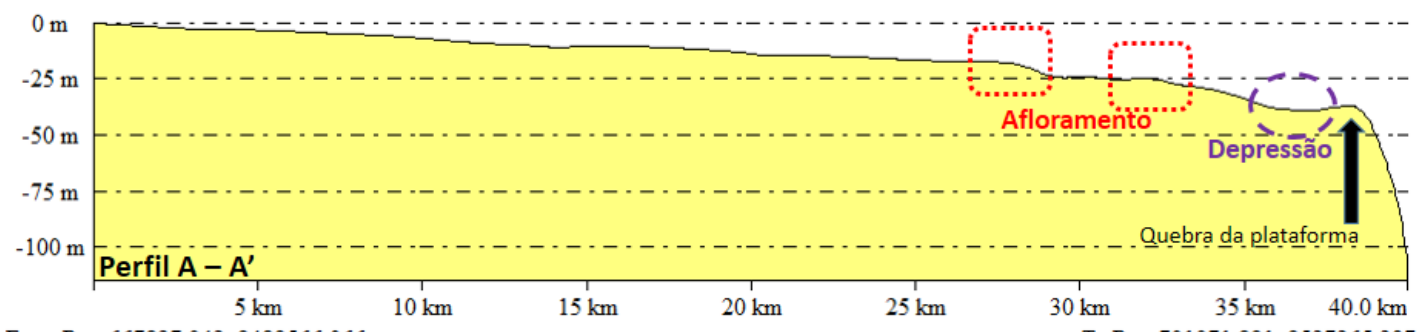

From Pos: 667837.042, 9489566.066 To Pos: 701071.891, 9527265.297

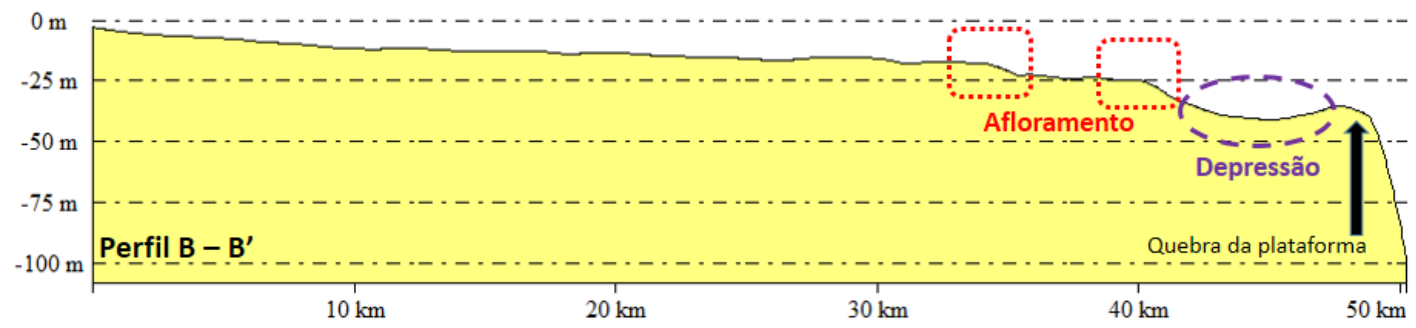

From Pos: $693300.558,9471212.494$

To Pos: $721740.328,9502959.214$

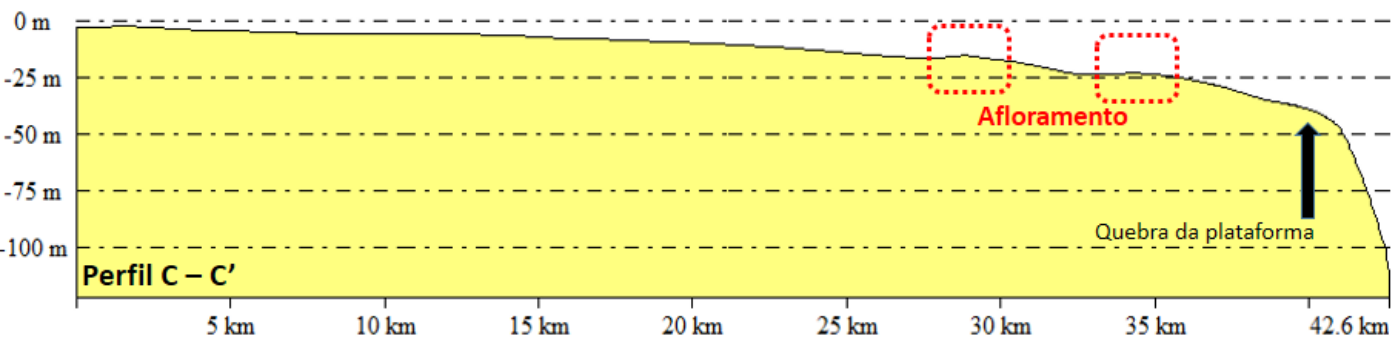

Figura 5 - Perfis perpendiculares à linha de costa. Fonte: Autor.

Já os perfis transversais D-D', EE' e F-F' (Fig. 6) apresentam uma variação brusca na morfologia da plataforma, de modo que podemos através dessa variação, dividir a área em setor leste e setor oeste. Essa variação de dá através de uma quebra na continuidade do relevo, já identificadas por Silva Filho (2007) e Abreu Neto (2017). O perfil D-D', mais próximo à costa, apresenta profundidades variando entre 6 e 10 metros no setor Oeste, enquanto que no setor Leste essa variação vai de 2 a $7,5 \quad \mathrm{~m}$ de profundidade. O perfil E-E' deixa mais clara a identificação da quebra na continuidade, além de ser possível a visualização do campo de dunas submersas que ocorrem na profundidade média de $16 \mathrm{~m}$. Por fim no perfil F-F', situado próximo a quebra da plataforma, é possível a visualização de reentrâncias, ravinas que possibilitam o fluxo de sedimentos da plataforma para o talude continental. 

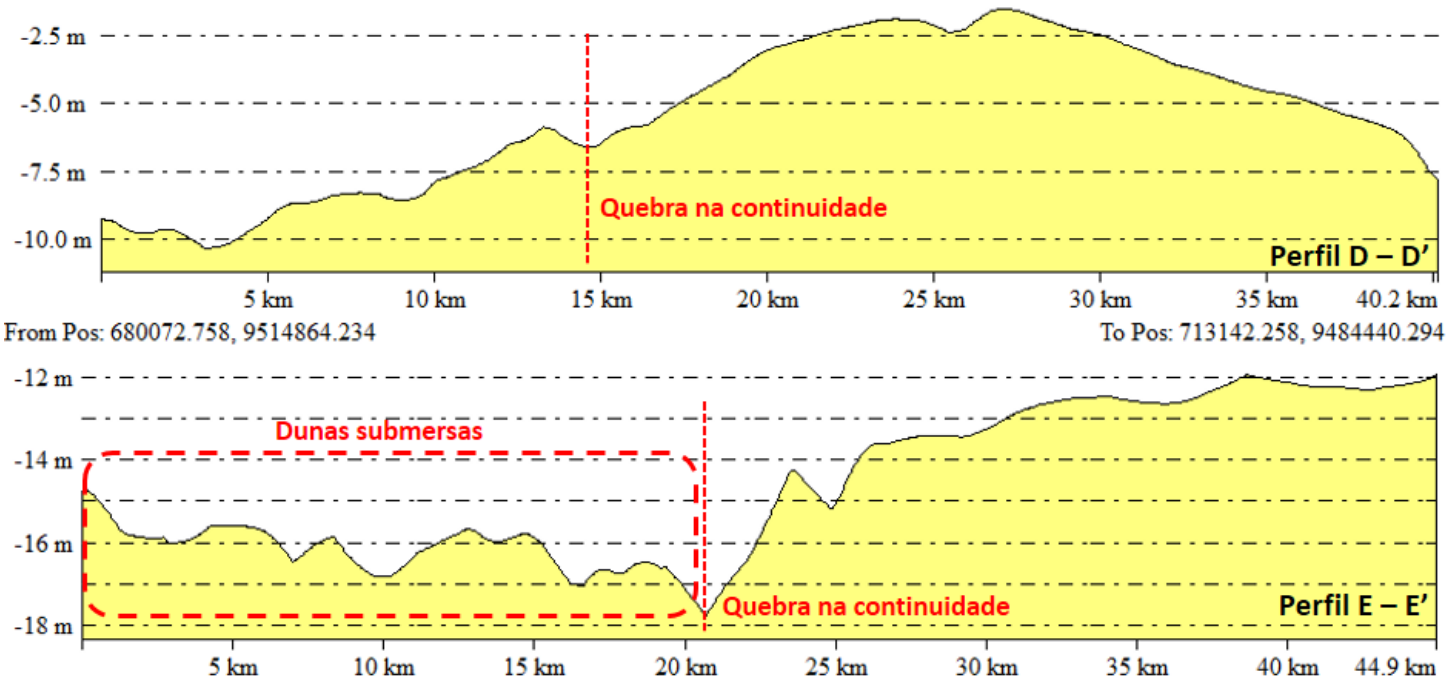

From Pos: 693961.948, 9526934.602 To Pos: $723559.151,9497668.094$

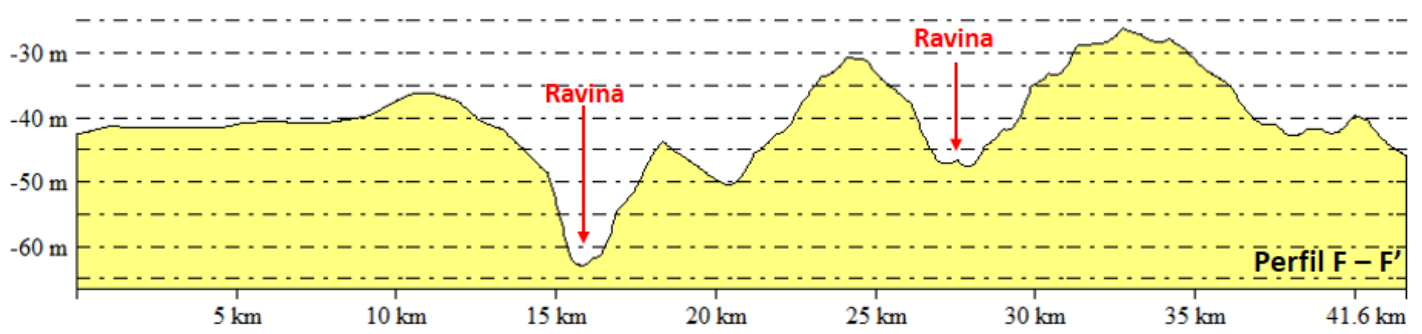

Figura 6 - Perfis paralelos à linha de costa. Fonte: Autor.

Então, através da análise dos perfis batimétricos pode ser observado comportamento da morfologia da plataforma que em sua parte interna apresenta maiores profundidades do lado oeste, bem como um relevo mais acidentado, pressupondo efeito de erosão marinha, já que existe em contato direto linha de costa em frente a plataforma, a ocorrência das falésias de Ponta Grossa sofrendo ação direta de ondas e da maré durante a preamar, ficando evidente através dos vários afloramentos rochosos que são testemunhos do recuo das falésias. Já no lado leste da plataforma a topografia se apresenta mais plana e rasa, possuindo em toda sua extensão flechas arenosas que podem ser evidências de estabilizações de antigas linhas de costa. Nessa mesma região da plataforma interna, temos a ela associada na área emersa a presença de uma extensa planície de maré apresentando a mesma orientação dos cordões arenosos submersos.

Já no perfil paralelo mais distante, a morfologia da plataforma se apresenta mais irregular, evidenciando ravinas na borda da plataforma, que possivelmente transporta sedimentos da plataforma para o talude continental.

\section{Declividade}

A quebra da plataforma continental do Ceará, segundo Freire (1985) apud Silva Filho (2004), fica por volta de uns $60 \mathrm{~m}$ de profundidade e, não se faz em um ponto, porém em uma zona de quebra. A oeste de Fortaleza, a zona de quebra é mais larga, com um estreitamento progressivo até a altura daquela cidade. À leste de Fortaleza, a zona de quebra apresenta-se mais estreita e com uma declividade mais acentuada.

A localização da quebra da plataforma continental em frente ao 
município de Icapuí fica situada a uma profundidade média de $40 \mathrm{~m}$ e a uma distância média de $45 \mathrm{~km}$ da linha de costa. Tais resultados mostram que a plataforma continental em Icapuí (Fig. 7 ), com uma declividade média de $1^{\circ}$, se apresenta de forma muito plana e com uma média de profundidade abaixo da média da plataforma continental do resto do estado do Ceará, que possui uma média de $60 \mathrm{~m}$. Dessa maneira, tais características influenciam diretamente na dinâmica da plataforma e vai condicionar a morfologia e processos de sedimentação da área.

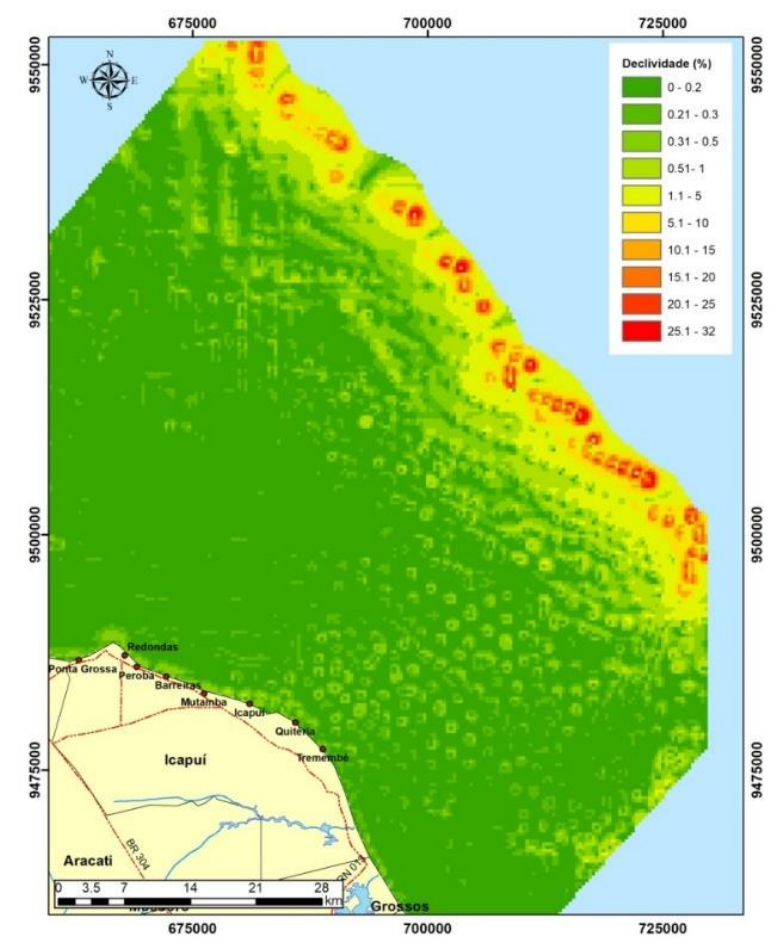

Figura 7 - Mapa de declividade da plataforma continental de Icapuí. Fonte: Abreu Neto, 2017.

A plataforma interna apresenta declividade média de $0.5^{\circ}$, sendo mais plana no lado oeste e com uma maior variação no leste, este último devido à presença das cristas de praia submersas. Já na plataforma externa, ocorre um aumento da declividade para uma média de $1.5^{\circ}$, que se intensifica na zona de quebra que de maneira mais abrupta nas extremidades da plataforma e de maneira mais suave no centro, como pode ser verificado nos perfis perpendiculares, onde os valores variam de $5^{\circ}$ até $32^{\circ}$.

Outro detalhe que pode ser visualizado no mapa de declividade é a ocorrência de variações na declividade no setor leste da plataforma interna, que apresentam padrão de forma e distribuição análogo aos das cristas de praia existentes na planície de maré de Icapuí.

A declividade da plataforma apresenta orientação predominante no sentido N e NE (Fig. 8), mostrando que o sentido da inclinação da plataforma se dá em direção ao interior da bacia oceânica. A orientação da declividade se apresentou mais difusa, exatamente onde temos a presença do campo de dunas submersas, que tem direção W-SW predominante, possuindo o mesmo sentido de deslocamento das correntes. 


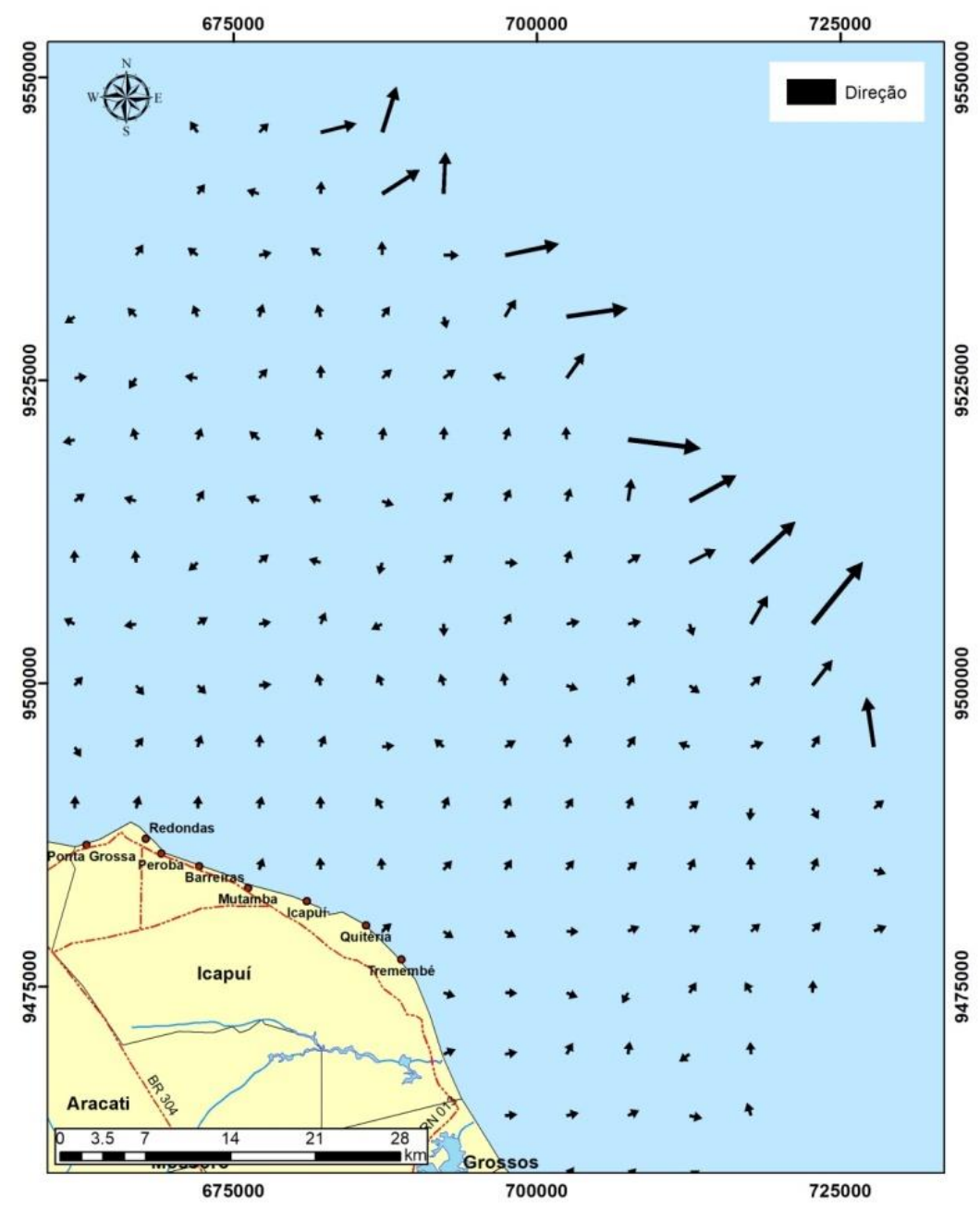

Figura 8 - Mapa de orientação da declividade da plataforma continental de Icapuí, onde setas maiores representam maior declividade. Fonte: Abreu Neto, 2017.

\section{Modelo digital de terreno da plataforma continental}

Com o grid criado foi gerado o MDT (Figura 9), onde podem ser visualizadas as feições da plataforma, com destaque para a quebra da plataforma e de pequenas reentrâncias que possibilitam o fluxo de sedimentos para o talude continental, com destaque para dois cânions de maior expressão. A presença do campo de dunas submersas também pode ser identificada no modelo e próximo a elas pode também ser visualizado o recife. 


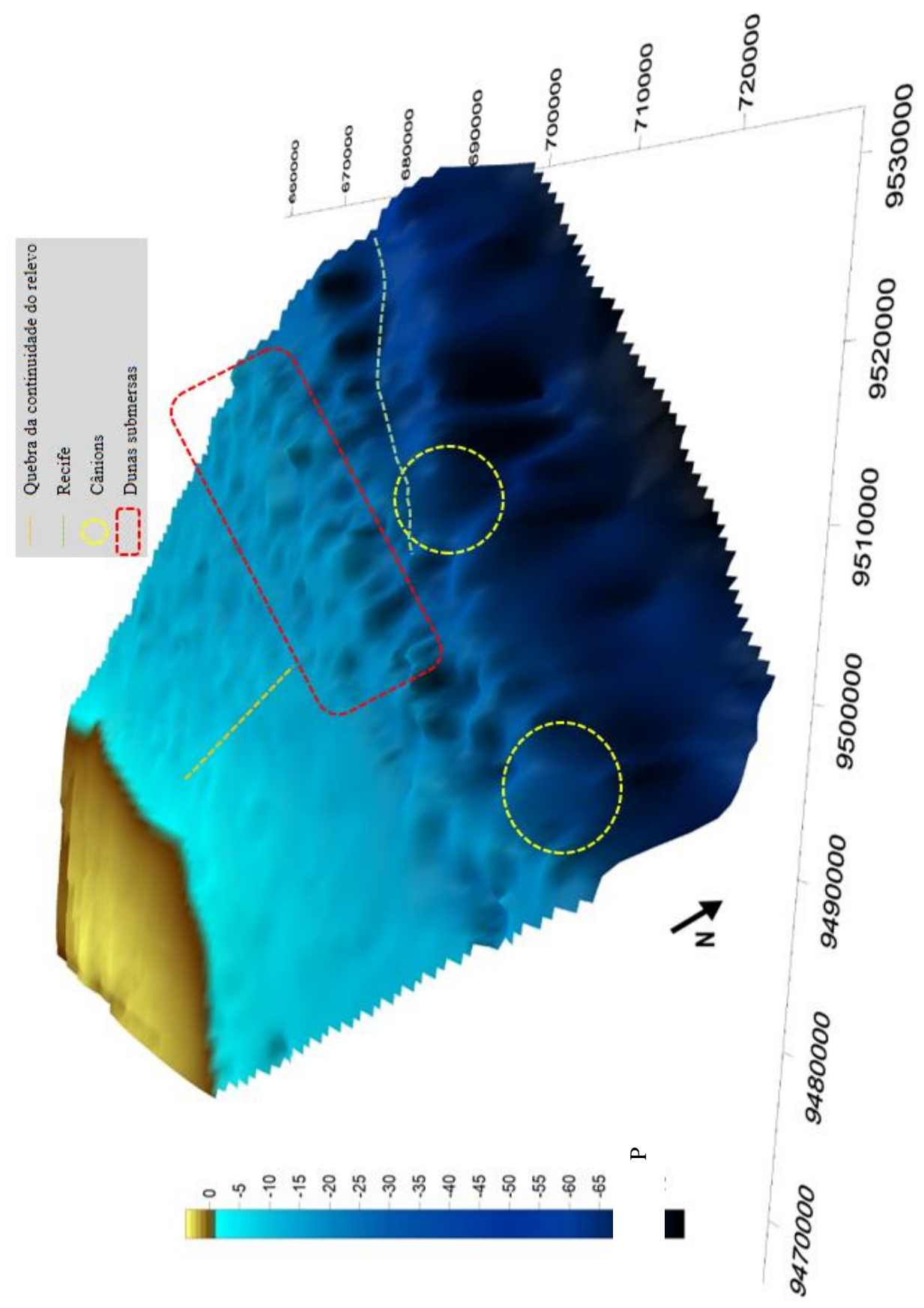

Figura 9 - Modelo digital de terreno (MDT) da plataforma continental de Icapuí. Fonte: Abreu Neto, 2017.

\section{DISCUSSÃO DOS RESULTADOS}

A partir dos resultados obtidos é possível que a morfologia da área apresenta um caráter predominantemente plano apesar das inúmeras estruturas submersas identificadas e se apresenta mais estreita e menos profunda do que média do resto do estado do Ceará.

A direção da declividade, apesar de algumas variações causadas por estruturas como o campo de dunas submersas, apresenta direção predominante para o interior da bacia oceânica, bem como a maior variação na 
declividade na plataforma externa e zona de quebra.

O campo de dunas submersas ocupa grande parte da plataforma externa oeste com altura média de $2 \mathrm{~m}$ e largura média de $500 \mathrm{~m}$, sendo limitada ao norte pela presença do afloramento que se encontra paralelo à linha de costa que, como já mencionado, se apresenta na forma de degraus e com configuração que remete a antigas linhas de costa. Ocorre entre os $15 \mathrm{~m}$ e os $25 \mathrm{~m}$ de profundidade e possui uma extensão de aproximadamente $22 \mathrm{~km}$.

Já no setor leste da plataforma interna predomina na área a presença das cristas de praia submersas, que apresentam padrão análogo às crista de praia existentes na planície de maré adjacente, possivelmente resultado de antigas linhas de costa que foram afogadas devido às flutuações do nível do mar.

\section{CONCLUSÕES}

Os resultados obtidos pelos dados batimétricos apresentaram resultados satisfatórios, tornando possível identificar as estruturas mais expressivas da plataforma continental de Icapuí, como campo de dunas submersas, as cristas de praia no setor leste da plataforma interna, o extenso recife na plataforma externa, a quebra na continuidade do relevo submerso e a zona de quebra da plataforma continental da área.

Devido às formas de fundo identificadas e seus padrões de ocorrência, é possível que esses afloramentos, cristas de praia submersas e aparentes resultados de ações erosivas tenham estreita relação com as flutuações do nível mar, tornando a plataforma continental de Icapuí, uma região de interesse para a compreensão de tais eventos.

Recomenda-se assim, um levantamento batimétrico de maior detalhe, associado a outros tipos de análise como estudos geofísicos e sedimentológicos, que integrados, sirvam como forma de obter mais informações sobre a área.

\section{Agradecimentos}

Este trabalho foi realizado com a ajuda da CAPES, através do fornecimento de bolsa de estudos, do Laboratório de Geologia Marinha e Aplicada, por fornecer a infraestrutura e os dados necessários e ao Programa de Pós graduação em Geologia da UFC.

\section{REFERÊNCIAS}

Abreu Neto, J. C. de., 2017. Geodiversidade da plataforma continental de Icapuí, Ceará: uma proposta de identificação de áreas chave em ambientes marinhos. Tese de doutorado, Programa de Pós-graduação em Geologia UFC. 125p.

ANP. Bacia Potiguar. Em http://www.brasilrounds.gov.br/round2/arquivos_r2 /Mapas/bacia/Bacia_Potiguar.pdf. Acesso em: outubro/2016.

Barros, E. L., 2014. Caracterização Faciológica da Plataforma Continental Interna do Município de Icapuí, Ceará. Dissertação de Mestrado, Universidade Federal do Ceará, Fortaleza. 105p.

Batista Neto, J.A.; Silva, C.G., 2004. Morfologia do fundo oceânico. In: Batista Neto,J.A.; Ponzi, V.R.A.; Sichel, S.E. (Org.). Introdução à geologia marinha. Rio de Janeiro: Interciência, p.31-51.

Coutinho, P. N., 1996. Levantamento do estado da arte da pesquisa dos recursos vivos marinhos do Brasil - Oceanografia Geológica. Programa Revizee - SECIRN, 80p. 
Freire, G. S. S., 1985. Geologia Marinha da Plataforma Continental do Estado do Ceará. Dissertação de Mestrado. Pós-Graduação em Geociências. Departamento de Geologia. Universidade Federal de Pernambuco. Recife. 162p.

Freire, G. S. S.; Cavalcanti, V. M. M., 1998. A cobertura sedimentar Quaternária da Plataforma Continental do Estado do Ceará. Fortaleza: DNPM $10^{\circ}$ Distrito/UFC. Dep. Geol. Lab. de Geol. Mar. Apl. 85p.

Kennett, J. P., 1982. Marine Geology. Prentice Hall Inc. New Jersey. $813 p$.

Meireles, A. J. de A.; Santos, A.M. F. dos., 2012. Atlas de Icapuí. $1^{\circ}$ Ed. Fortaleza, CE: Editora Brasil Cidadão. 77p.

Monteiro, L. H. U. Feições superficiais da plataforma continental cearense entre o litoral de Fortaleza e Icapuí. Tese de doutorado. Recife, 2011. $181 \mathrm{p}$.

Oliveira, P. R. A., 2009. Caracterização morfológica e sedimentológica da plataforma, continental brasileira adjacente aos municípios de Fortim, Aracati e Icapuí- CE. Dissertação (Mestrado em Geodinâmica; Geofísica) Universidade Federal do Rio Grande do Norte, Natal. 131p.

Oliveira, M. M. N. de., 2012. Aspectos morfológicos e sedimentares associados à dinâmica do Litoral
Oeste de Icapuí, Ceará. Dissertação de Mestrado Universidade Federal do Ceará. 188p.

Silva Filho, W. F., 2004. Domínios morfoestruturais da plataforma continental do Estado do Ceará. Tese de Doutorado, Universidade Federal do Rio Grande do Sul, Porto Alegre, 288p.

Silva Filho, W.F.; Castro, D.L.; Corrêa, I. C. S., 2007. Estruturas rasas na margem equatorial ao largo do Nordeste brasileiro (estado do Ceará): análise de relevo e anomalias gravimétricas residuais. Revista Brasileira de Geofísica,25(Supl. 1):65-77.

Silveira, T. de A.; Portugal, J.L.; Souza, F. de A. S. de; Lacerda, J. M. F. de., 2003. Análise de estatística espacial em Sistemas de Informação Geográfica (SIG): uma proposta metodológica aplicada à construção de superfícies batimétricas. V Simpósio Brasileiro de Ciências Geodésicas e Tecnologias da Geoinformação. Recife, 2014.

Tessler, M. G. \& Mahiques, M. M., 2000. Processos oceânicos e a fisiografia dos fundos marinhos. In: Teixeira, W.; Toledo, M. C. M.; Fairchild, T. R.; Taioli, F. (Org.). Decifrando a Terra. São Paulo: Oficina de Textos. 624p. 